\title{
Evaluation of dietary betaine in lactating Holstein cows subjected to heat stress
}

\author{
L. W. Hall, ${ }^{* 1}$ F. R. Dunshea,† J. D. Allen, ${ }^{* 2}$ S. Rungruang, ${ }^{* 3}$ J. L. Collier, ${ }^{*}$ N. M. Long, ${ }^{* 4}$ and R. J. Collier*5 \\ ${ }^{*}$ School of Animal and Comparative Biomedical Sciences, The University of Arizona, Tucson 85719 \\ †Faculty of Veterinary and Agricultural Sciences, The University of Melbourne, Parkville, VIC 3010, Australia
}

\begin{abstract}
Betaine (BET), a natural, organic osmolyte, improves cellular efficiency by acting as a chaperone, refolding denatured proteins. To test if dietary BET reduced the effect of heat stress (HS) in lactating dairy cows, multiparous, lactating Holstein cows $(\mathrm{n}=24)$ were blocked by days in milk (101.4 $\pm 8.6 \mathrm{~d})$ and randomly assigned to 1 of 3 daily intakes of dietary BET: the control $(\mathrm{CON})$ group received no BET, mid intake (MID) received $57 \mathrm{mg}$ of $\mathrm{BET} / \mathrm{kg}$ of body weight, and high dose (HI) received $114 \mathrm{mg}$ of $\mathrm{BET} / \mathrm{kg}$ of body weight. Cows were fed twice daily and BET was top-dressed at each feeding. Cows were milked 2 times/d and milk samples were taken daily for analysis. Milk components, yield, feed intake, and water intake records were taken daily. Rectal temperature and respiration rate were taken 3 times/d at 0600, 1400, and $1800 \mathrm{~h}$. Cows were housed in environmentally controlled rooms and were allowed acclimation for $7 \mathrm{~d}$ at thermoneutral (TN) conditions with a mean temperature-humidity index of 56.6. Cows were then exposed to $7 \mathrm{~d}$ of TN followed by $7 \mathrm{~d}$ of HS represented by a temperature-humidity index of 71.5 for $14 \mathrm{~d}$. This was followed by a recovery period of 3 $\mathrm{d}$ at TN. Dietary BET increased milk yield during the TN period. No differences were found between BET and $\mathrm{CON}$ in total milk production or milk composition during HS. The increase in water intake during HS was not as great for cows fed BET compared with controls. The cows on CON diets had higher p.m. respiration rate than both MID and HI BET during HS, but lower

\footnotetext{
Received October 11, 2015.

Accepted August 9, 2016.

${ }^{1}$ Current address: Intermountain Farmers Association, PO Box 96,

${ }^{2}$ Current address: Department of Agricultural Sciences, Northwest

${ }^{3}$ Current address: Charoen Pokphand Group, Bangkok, Thailand,

${ }^{4}$ Current address: Department of Animal and Veterinary Sciences,

${ }^{5}$ Corresponding author: rcollier@ag.arizona.edu
} Nephi, UT 84648. Missouri State University, Maryville, MO 64468. 10500. College of Agriculture, Forestry and Life Sciences, Clemson University, SC 29634.
\end{abstract}

rectal temperature compared with BET. No difference was found in serum glucose during $\mathrm{TN}$, but cows given HI had elevated glucose levels during HS compared with CON. No differences were found in serum insulin levels between $\mathrm{CON}$ and BET but an intake by environment interaction was present with insulin increasing in HItreated lactating dairy cows during HS. The heat shock response [heat shock protein (HSP) 27 and HSP70] was upregulated in bovine mammary epithelial cells in vitro. Blood leukocyte HSP27 was downregulated at the HI dose under TN conditions and HSP70 was upregulated at the HI dose and this effect was increased by HS. No effect was seen with the MID dose with HSP27 or HSP70. The lack of effect of BET at MID may be associated with uptake across the gut. We conclude that BET increased milk production under TN conditions and was associated with reduced feed and water intake and slightly increased body temperatures during HS of cows fed BET. The effect of BET on milk production was lost during HS with HI BET, whereas serum glucose levels increased during HS.

Key words: dairy cow, betaine, heat stress, blood glucose

\section{INTRODUCTION}

Betaine (trimethylglycine) is a zwitterion that has many activities that may reduce the effect of heat stress (HS) in lactating dairy cows and improve general production. These include the fact that betaine (BET) is an organic osmolyte (Hammer and Baltz, 2002), is a molecular chaperone (Sharma et al., 2009), has been shown to decrease susceptibility of microbial populations to stress (Lai and Lai, 2011), acts as an antimicrobial to some bacteria such as Salmonella typhimurium (Lindstedt et al., 1990), can be used as a nutrient (Craig, 2004), and has been demonstrated to increase milk production when fed (Wang et al., 2010). Betaine is transported across cell membranes utilizing a $\mathrm{Na}(+)$-coupled betaine-specific transporter of the betaine-choline-carnitine transporter family involved in the response to hyperosmotic stress (Perez et al., 
2011). This osmoregulation is also seen in microbial populations and has been shown to promote favorable bacterial growth under osmotic stress conditions (Diamant et al., 2001; Wdowiak-Wrobel et al., 2013) including fluctuations in $\mathrm{pH}$ (Laloknam et al., 2006). Betaine has a net neutral charge, but has a region of positive and negative charges. This allows BET to hold water molecules (intracellular) against a concentration gradient, yet the affinity is not so much that the water is unavailable to the cell.

Osmolytes like BET can prevent heat-induced damage by stabilizing cellular proteins, refolding unfolded peptides and allowing the disaggregation and refolding of heat-damaged proteins (Diamant et al., 2003). Glycine BET has been shown to increase the metabolic efficiency of glucose in Escherichia coli cells stressed with salt (Metris et al., 2014). Another advantage that organic osmolytes have over salts is that they do not interfere with native enzymatic activity within cells (Nakanishi et al., 1990).

Betaine has 2 potential sites of action in lactating ruminants: mammalian cells and the microbes in the gastrointestinal tract. Under different types of stress, both microbial and animal cells increase uptake of exogenous BET (Nakanishi et al., 1990). The benefits of supplementing BET in lactating dairy cow diets have been demonstrated under thermoneutral (TN) conditions. These include increased milk production (Wang et al., 2010; Peterson et al., 2012), increased VFA production, and higher FCM yield (Wang et al., 2010). Rumen microbial utilization and degradation of BET would limit availability to rumen epithelial or other nondigestive tract cell types. However, Nakai et al. (2013) indicated that fed BET is found in the duodenal digesta, indicating that some BET escapes the rumen.

We hypothesize that dietary BET will reduce the effect of $\mathrm{HS}$ on rectal temperature and respiration rate and improve cellular thermotolerance by increasing heat shock protein (HSP) production in vivo in mammary epithelial cells and white blood cells. Furthermore, this improvement in thermotolerance would result in greater production of lactating dairy cows. The objective of this study was to evaluate the role of dietary BET in improving thermotolerance in lactating heat-stressed dairy cows.

\section{MATERIALS AND METHODS}

\section{Cell Culture}

Primary bovine mammary epithelial cells (BMEC) were harvested, isolated, and prepared according to Stiening et al. (2008). The cells were thawed from liquid nitrogen storage, suspended in Dulbecco's modified
Eagle medium/F-12 (Gibco, Life Technologies, Grand Island, NY), mixed in neutralized collagen, and cultured (Stiening et al., 2008) in 24-well plates (Falcon, BD Biosciences, San Jose, CA). The collagen was added in 2 steps, as the base layer was allowed to gel for 5 min and the second layer containing the cells was seeded into each well in a final volume of $500 \mu \mathrm{L}$. The BMEC were grown in collagen that was extracted from rat-tails and allowed to grow at $37^{\circ} \mathrm{C}$ for $7 \mathrm{~d}$ (McGrath, 1987; Stiening et al., 2008) with media changed every $48 \mathrm{~h}$.

The serum-free Dulbecco's modified Eagle medium/F-12 medium contained 0.1\% BSA, antibioticantimycotic $(100 \mathrm{U} / \mathrm{mL}$ of penicillin, $100 \mu \mathrm{g} / \mathrm{mL}$ of streptomycin, and $0.25 \mu \mathrm{g} / \mathrm{mL}$ of amphotericin $\mathrm{B}$; 15240, Invitrogen Corp., Carlsbad, CA). The added growth factors included IGF-1 (recombinant human, $100 \mathrm{ng} / \mathrm{mL}$, NIDDK, Torrance, CA), epidermal growth factor, (EGF, recombinant human, $25 \mathrm{ng} / \mathrm{mL}$, Invitrogen Corp.), and $500 \mathrm{ng}$ of progesterone (Sigma-Aldrich, St. Louis, MO; Hernandez et al., 2011) per $100 \mathrm{~mL}$ of medium.

On d 8, cells were treated with 0 or $25 \mathrm{~m} M$ BET within the same culture plate, with one set of plates being subjected to $\mathrm{HS}\left(42^{\circ} \mathrm{C}\right)$ and the other set remaining at $\mathrm{TN}\left(37^{\circ} \mathrm{C}\right)$ for $24 \mathrm{~h}$. Cells were continuously maintained at these temperatures for $24 \mathrm{~h}$ and then harvested. There were 6 wells per BET treatment per environment. Two wells of each subset (treatment and environment) were combined and placed in TRIzol reagent (Life Technologies, Carlsbad, CA) so that there were triplicate biological samples. Ribonucleic acid was isolated from triplicate samples, treated with DNase (DNase I, Invitrogen Corp.), cDNA was synthesized (iScript cDNA Synthesis kit, Bio-Rad, Hercules, CA), and quantitative real-time PCR using the Bio Rad iQ5 optical system (Bio-Rad) was conducted following the procedures described by Hernandez et al. (2011). The expression of HSP70 and HSP27 was quantified using the calibrator gene 40S ribosomal protein S9 (RPS9) for calculating gene expression data based on the $2^{-\Delta \Delta \mathrm{Ct}}$ method (Livak and Schmittgen, 2001). A one-way ANOVA was conducted on $\triangle \mathrm{Ct}$ (cycle threshold) value with the PROC MIXED procedure of SAS (SAS Institute Inc., Cary, NC). Data are presented as fold change.

\section{Lactation Study}

This study was conducted on a protocol approved by the Institutional Animal Care and Use Committee of the University of Arizona. Cows for this study were obtained from Caballero Dairy, Eloy, Arizona. Twentyfour multiparous Holstein cows were blocked by DIM $(101.4 \pm 8.6 \mathrm{~d})$ and randomly assigned to treatment 
in a replicated $2 \times 3$ factorial design (environment by intake of BET). Intakes of BET were CON (0 mg of $\mathrm{BET} / \mathrm{kg}$ of $\mathrm{BW}$ per d), MID intake BET (57 mg of $\mathrm{BET} / \mathrm{kg}$ of BW per d), and HI intake BET (114 mg $\mathrm{BET} / \mathrm{kg}$ of BW per d). Cows selected were also balanced for parity and milk yield across dietary treatments. After selection, cattle were shipped $75 \mathrm{~km}$ to the University of Arizona, William J. Parker Agricultural Research Center (ARC) for $31 \mathrm{~d}$. Upon arrival at the ARC, cows were weighed, fitted with a halter, and randomly assigned to a room and tiestall. Animals were housed in 2 controlled environment rooms (6 cows each, balanced for intake of BET) and subjected to TN and HS conditions (Figure 1). The 2 environmental rooms had the same temperature, humidity, and light/dark schedule. The environmental conditions in both rooms were controlled by the same computer and were verified 3 times per day when respiration rate $(\mathbf{R R})$ and rectal temperature (RT) were measured. The experimental design was for all cows in both rooms to be at TN for $14 \mathrm{~d}$; then the environment was changed to HS for all cows at the same time for an additional $14 \mathrm{~d}$. Upon completion of the environmental phase of the study, the first 12 cows were returned to the dairy and the study was replicated with the remaining set of 12 cows at the dairy for a total of 24 cows. Each room had 2 each of CON, MID, and HI BET intake cows. The cows were given $7 \mathrm{~d}$ at $\mathrm{TN}$ to adapt (acclimation period) to the new diet, the tiestall, and new milking procedures. The cows were then subjected to an additional $7 \mathrm{~d}$ of $\mathrm{TN}$ followed by the HS period that lasted $14 \mathrm{~d}$. At the end of each study, the animals were given $3 \mathrm{~d}$ of post-HS recovery before returning to the dairy.

During the study, cows were individually fed preweighed amounts of TMR 2 times/d at 0500 and $1700 \mathrm{~h}$ (Table 1). Treatment (BET, 94\% pure) was top-dressed onto rations and the quantity was based on individual BW and divided into 2 equal half intakes fed at each feeding). The BET was mixed into the top one-third of all rations with $50 \mathrm{~mL}$ of cane molasses as a binder. Control diets included $50 \mathrm{~mL}$ of cane molasses top dressed onto the ration. Feed refusals were removed and weighed at $1645 \mathrm{~h}$ daily. Fresh water was metered and offered ad libitum, individual water consumption (L/d) was recorded. Cows were milked between 0530 and $0630 \mathrm{~h}$, and from 1730 to $1830 \mathrm{~h}$ daily. Milk weight was recorded at each milking. Milk samples were taken at the morning milking and individually stored with a preservative (bronopol tablet, D\&F Control Systems, San Ramon, CA) at $4^{\circ} \mathrm{C}$. The individual daily samples were stored at $5^{\circ} \mathrm{C}$ until analyzed. Aliquots were analyzed by Arizona DHIA (Tempe, AZ) by infrared for butter fat, protein, SCC, lactose, and SNF (= TS - fat \%). Anhydrous glycine BET, BetafinS4 (93\% pure, Da- nisco Animal Nutrition, St. Louis, MO), a byproduct of sugar beet production, was the source of the fed supplement. The base TMR was alfalfa hay based with steam flaked corn, whole cottonseed, bypass fat (Maxxer, Tarome Inc., Eloy, AZ), distillers grain, water, and a high producer mineral premix (Table 1 ). The TMR was $47 \%$ moisture with $65 \%$ roughage and $35 \%$ concentrate. The ration was balanced to match the energy level of the silage-based diet fed to the cows at the dairy before arrival at the ARC (Table 1). The ration for each day was mixed in the morning. The morning ration was fed immediately and the evening ration was stored at $5{ }^{\circ} \mathrm{C}$ until fed after the evening milking.

Physiological parameters were recorded $3 \times$ daily $(0600,1400,1800 \mathrm{~h})$ for the 28-d experimental period. The RT was measured using a GLA M700 digital thermometer (GLA Agricultural Electronics, San Luis Obispo, CA). Respiration rates were measured by counting flank movements for $15 \mathrm{~s}$ and multiplying by 4

\section{Thermoneutral}
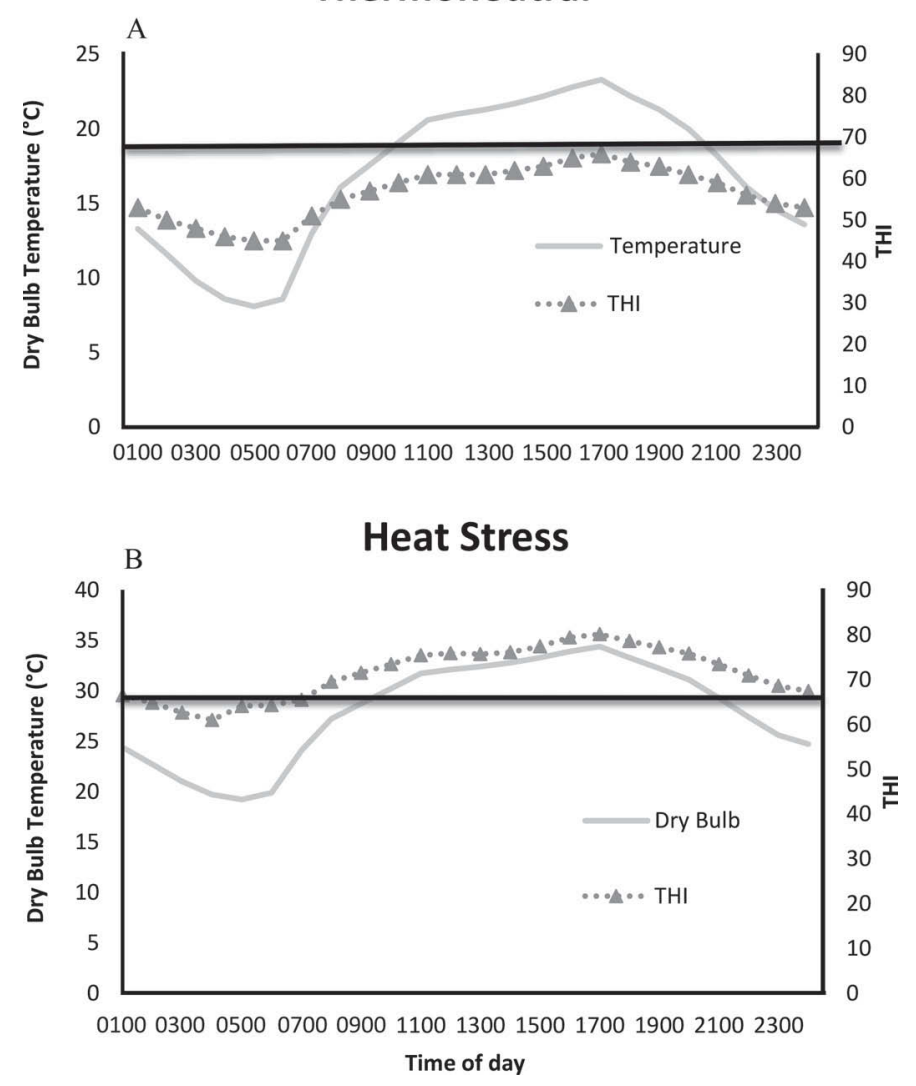

Figure 1. Diurnal environmental conditions during thermoneutral (TN; A) and heat stress (HS; B) components of the study. Black line indicates the threshold temperature-humidity index (THI; 68) for HS in lactating dairy cows. (B) Diurnal conditions during HS. Solid black line indicates the threshold THI (68) for HS in lactating dairy cows (respiration rate $\geq 60 \mathrm{bpm}$, rectal temperature $\geq 39^{\circ} \mathrm{C}$ ); Berman (2005), Zimbelman et al. (2009). 
to record as minutes when temperatures were recorded. Any cow with a rectal temperature over $40.5^{\circ} \mathrm{C}$ was removed from the environmental room and soaked with cold water for $5 \mathrm{~min}$. One cow met this criterion several times each day of HS and was subsequently removed from the study due to the inability to adapt to the stress.

\section{Blood Sampling}

On d 13 (TN) and d 21 (HS), coccygeal vessel blood samples were obtained from all animals. These samples were stored for analysis of serum glucose, serum insulin, and levels of HSP70 and HSP27 from the buffy coat. Samples were collected in BD Vacutainer tubes (BD, Franklin Lakes, NJ) with an 18-gauge transfer needle. During TN and HS, samples were collected every $4 \mathrm{~h}$ over a 24 -h period $(0400,0800,1200,1600,2000$, and $2400 \mathrm{~h}$ ). Samples for buffy coat and serum were collected in tubes containing sodium heparin, placed on ice, and centrifuged at $1,500 \times g$ for $15 \mathrm{~min}$ at $4^{\circ} \mathrm{C}$. Samples for serum were collected in blank tubes, stored at $4^{\circ} \mathrm{C}$ for $12 \mathrm{~h}$, and centrifuged at $1,500 \times g$ for $15 \mathrm{~min}$ at $4^{\circ} \mathrm{C}$ serum was stored at $-80^{\circ} \mathrm{C}$ until analysis.

The buffy coat was removed and placed into microfuge tubes containing Trizol LS (Life Technologies, Grand Island, NY) and stored at $-80^{\circ} \mathrm{C}$ until analysis. Buffy coat samples were subsequently thawed, homogenized, RNA was extracted using the Trizol LS method and purified using the Omega E.Z.N.A. Total RNA Kit

Table 1. Ingredients and chemical composition of the diet

\begin{tabular}{lc}
\hline Item & \% of DM \\
\hline Alfalfa hay & 65.02 \\
Corn (steam flaked) & 22.12 \\
Whole cottonseed & 7.28 \\
Distillers grains (dry) & 2.58 \\
Supplement RS-1299 $^{2}$ & 2.04 \\
Maxxer $^{3}$ & 0.96 \\
Chemical analysis & \\
CP (\%) & 19.51 \\
NDF (\%) & 27.13 \\
ADF (\%) & 20.48 \\
Fat (\%) & 4.77 \\
DM (\%) & 53.00 \\
NE $_{\mathrm{L}}{ }^{4}(\mathrm{Mcal} / \mathrm{kg})$ & 1.74
\end{tabular}

${ }^{1}$ Diet DM averaged $53 \%$ by weight of DM and moisture including added water.

${ }^{2}$ The supplement (Dairy Nutrition Services, Chandler, AZ) contained $1.14 \%$ fat, $10.42 \%$ Ca, $4.49 \%$ P, $3.80 \% \mathrm{Mg}, 0.49 \% \mathrm{~S}, 0.19 \% \mathrm{~K}, 15.83 \%$ $\mathrm{Na}, 7.52 \% \mathrm{Cl}, 2,029.06 \mathrm{mg} / \mathrm{kg} \mathrm{Zn}, 1,991.82 \mathrm{mg} / \mathrm{kg}$ of Mn, $974.24 \mathrm{mg} /$ $\mathrm{kg}$ of $\mathrm{Fe}, 583.45 \mathrm{mg} / \mathrm{kg}$ of $\mathrm{Cu}, 67.86 \mathrm{mg} / \mathrm{kg}$ of Co, $12.28 \mathrm{mg} / \mathrm{kg}$ of Se, $6.81 \mathrm{mg} / \mathrm{kg}$ of Mo, $43.68 \mathrm{mg} / \mathrm{kg}$ of I, $304.9 \mathrm{IU} / \mathrm{g}$ of vitamin A, 30.2 $\mathrm{IU} / \mathrm{g}$ of vitamin $\mathrm{D}$, and $1.0 \mathrm{IU} / \mathrm{g}$ of vitamin $\mathrm{E}$ on a DM basis.

${ }^{3}$ Calcium salts of palm oil (Tarome Inc., Eloy, AZ).

${ }^{4} \mathrm{NE}_{\mathrm{L}}$ was calculated by Dairy One (http://dairyone.com/) based on analysis of TMR samples.
(Omega Bio-Tek, Norcross, GA). Clean RNA was quantified using the NanoDrop Spectrophotometer ND-1000 (NanoDrop, Wilmington, DE), treated with DNase I (amplification grade, Invitrogen), and synthesized into cDNA using iScript (Bio-Rad). Gene expression was estimated using quantitative PCR.

Serum insulin levels were determined using a Siemens Medical Solutions Diagnostics (Los Angeles, CA) RIA, and serum glucose was quantified using a colorimetric assay (Pointe Scientific Inc., Canton, MI), both described and validated by Long and Schafer (2013). The intra- and interassay coefficients of variation were less than 10 and $5 \%$ for insulin and 5 and $7 \%$ for glucose, respectively.

\section{Statistical Analysis}

Dependent variables including production, physiological, and blood data were analyzed as a $2 \times 3$ replicated factorial design using the MIXED procedure (SAS Institute Inc.) with the LSMEANS and PDIFF options within each environmental period as the REPEATED option with day within period as the repeated measure, animal was nested within treatment, using a compound symmetry covariate structure. Fixed effects included environment and level of BET inclusion. Linear and quadratic effects were analyzed using the CONTRAST option. Rectal temperatures were averaged per hour by day of trial. Animal was the experimental unit $(\mathrm{n}=23)$; one cow was unable to acclimate in the environmental chambers and was removed from the study. Measures on $\mathrm{d} 5$ to 7 were used as a covariate for production and physiological responses. Data were then also analyzed as percent change from covariate. Cattle typically do not reach their on-dairy production levels while housed in confinement, but by d 4 they acclimated and reached their peak ARC production.

\section{RESULTS AND DISCUSSION}

\section{In Vitro}

Following the $8 \mathrm{~d}$ of growth at $\mathrm{TN}$ conditions at $37^{\circ} \mathrm{C}$, half of the plates were moved to the HS condition, which was $42^{\circ} \mathrm{C}$. Cells were continuously maintained at these temperatures for $24 \mathrm{~h}$, and then harvested. The BMEC treated with BET (Figure 2) had visually greater growth and survival after HS. The proliferation and ductal development was visible and robust in BET-treated cells, whereas untreated control cultures contained collapsed ductal structures, which appeared to be undergoing atresia. Betaine decreased the expression of HSP27 and HSP70 during TN $(P<0.05)$. Gene expression of both HSP27 and HSP70 was higher in 

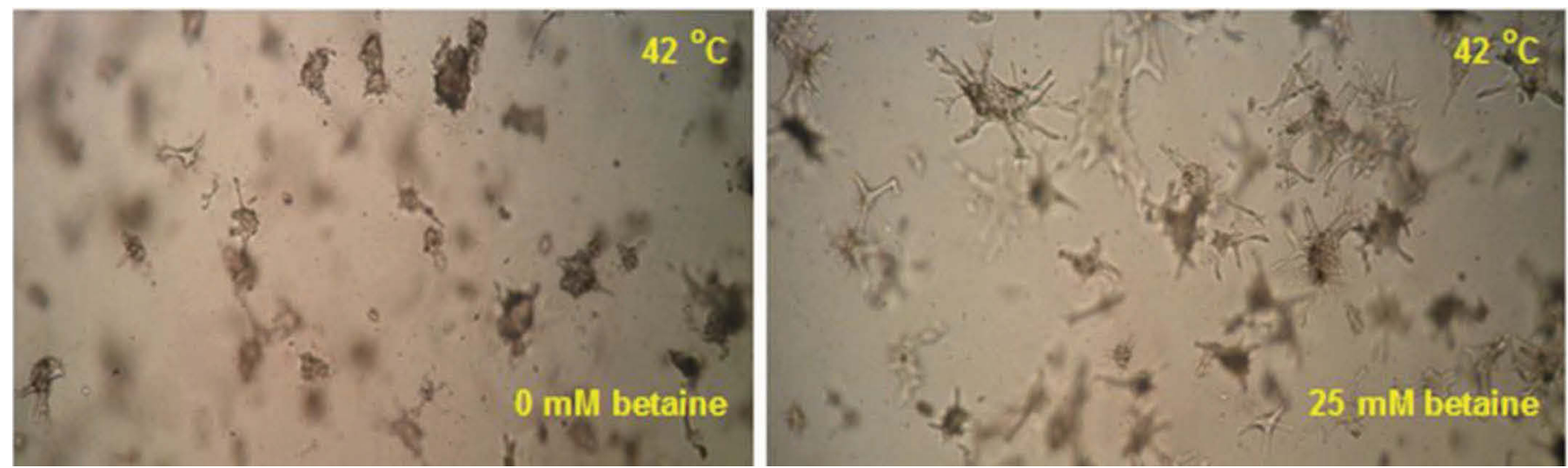

Figure 2. Images of primary bovine mammary epithelial cells (BMEC) in collagen after $8 \mathrm{~h}$ of exposure at $42^{\circ} \mathrm{C}$ treated with $0 \mathrm{~m} M$ betaine (A) or $25 \mathrm{~m} M$ betaine (B). Color version available online.

BET-treated cells $(P<0.01$, Figure 3$)$ compared with untreated controls during thermal shock.

The addition of $25 \mathrm{mM}$ BET to cell culture media improved thermotolerance of BMEC subjected to HS as measured by HSP27 and HSP70 gene expression and cell survival. Previously, Collier et al. (2006) reported
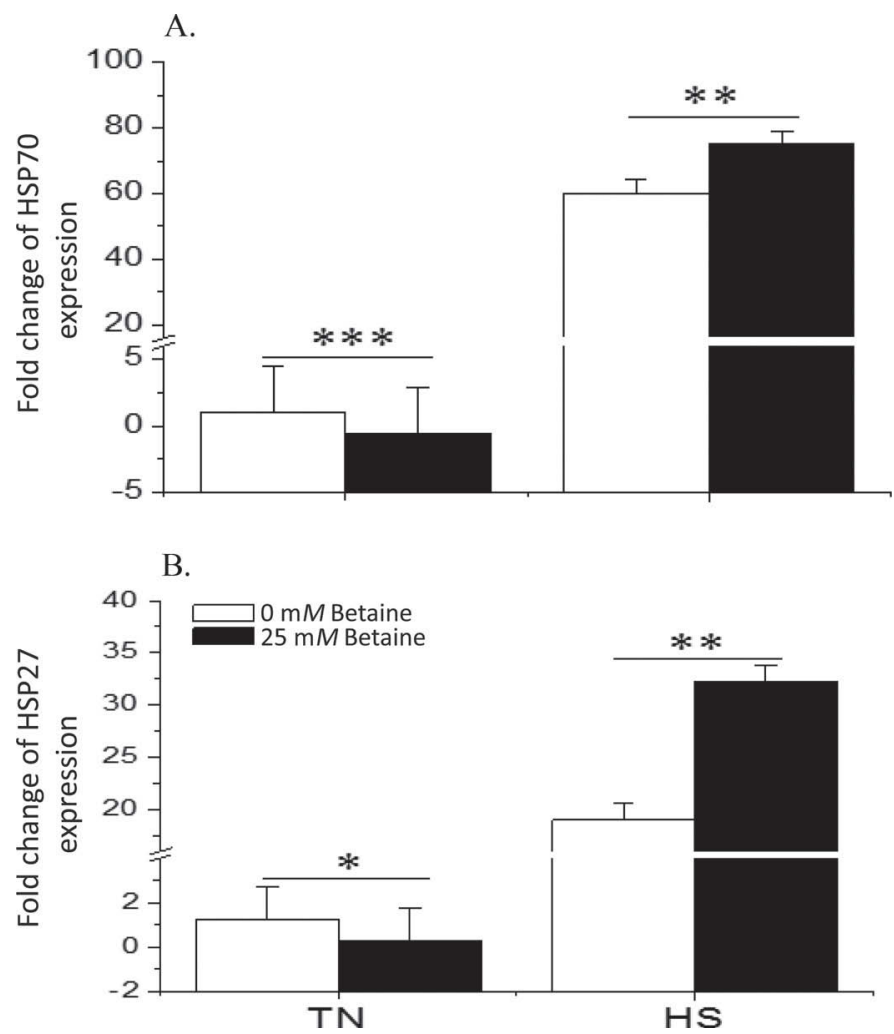

Figure 3. Expression of heat shock protein (HSP) 70 (A) and HSP27 (B) in primary bovine mammary epithelial (BMEC) cells treated with 0 or $25 \mathrm{~m} M$ betaine for $8 \mathrm{~h}$ at either 37 (thermoneutral; TN) or $42^{\circ} \mathrm{C}$ (heat stress; HS). ${ }^{*} P<0.05,{ }^{*} P<0.01$, ${ }^{*} * * P<0.001$. Error bars represent the SE of the LSM. that $\mathrm{BMEC}$ exposed to $42^{\circ} \mathrm{C}$ for $24 \mathrm{~h}$ had reduced growth and gene expression with increased cell death. Betaine appeared to partially protect primary BMEC from acute HS in vitro. The acquisition of the ability to increase heat shock protein synthesis is a fundamental component of the development of thermal tolerance (Collier et al., 2006, 2008).

The upregulated expression of mRNA for HSP27 and HSP70 during HS may be protective against apoptotic activity in treated cells and would leave fewer viable cells in untreated controls (0 $\mathrm{m} M$ BET $)$. Total DNA was not measured, but the images of BMEC cells in control medium following $24 \mathrm{~h}$ of heat shock (Figure 2) appear to have dead clusters of cells. This suggests that BET at a concentration of $25 \mathrm{mM}$ is able to partially protect cells for $24 \mathrm{~h}$ of continuous exposure to $42^{\circ} \mathrm{C}$ in vitro. In cell culture experiments using SV-3T3 mouse cells, Petronini et al. $(1992,1993)$ measured significant cell growth and protein synthesis in hyperosmotic medium when $25 \mathrm{~m} M$ BET was added. The concentration of BET in cell culture does not represent levels in vivo. The amount of BET needed to pass the rumen and gut microbes and enter the cells in cows is unknown. Future research should include measuring circulating BET concentrations in blood using a HPLC to better understand the physiologic concentrations of BET in vivo and their effect on osmoregulation and function as a molecular chaperone. This would demonstrate if BET is degraded in the rumen and what amount needs to be fed.

\section{In Vivo}

Environmental temperature-humidity index (THI) values during $\mathrm{TN}$ were below the HS threshold established for lactating dairy cows for $24 \mathrm{~h}$ a day, whereas THI values for HS were above the threshold for $17 \mathrm{~h}$ 
per day (Figure 1; Zimbelman et al., 2009). The RT and $\mathrm{RR}$ data at $1800 \mathrm{~h}$ are presented by treatment (CON, MID, and $\mathrm{HI}$ ) and environment (TN and $\mathrm{HS}$ ) in Table 2. Differences in environmental heat load were reflected in RT and RR for cows in this study, which were significantly higher in HS than TN at $1800 \mathrm{~h}$ (Table 2). The RT and RR of both CON and BET-treated cows indicated they had exceeded their thermal threshold and were experiencing mild to moderate HS. Cows experiencing mild to moderate HS displayed RR greater than 60 breaths per minute and RT greater than $39^{\circ} \mathrm{C}$ (Berman, 2005; Zimbelman et al., 2009). Feeding BET to lactating dairy cows did not alter RT during TN, but cows fed BET at the MID and HI intakes had elevated RT compared with CON at $1800 \mathrm{~h}$ (Table 2), and there was a BET $\times$ Env interaction $(P<0.04$; Table 2$)$. The $\mathrm{RR}$ of all dietary doses of BET were elevated by HS but were slightly lower in BET compared with CON cows at the MID and HI doses $(\mathrm{BET} \times$ Env interaction $=P<0.09$; Table 2) even though the RT were higher (Table 2).

Tests of significance for in vivo data are shown in Table 2. No linear or quadratic effects were found of treatment within RT and RR or in \% change of RT and $\mathrm{RR}$. Respiration rates were decreased by intake of BET during HS at $1800 \mathrm{~h}(P<0.01$; Table 2). The mean RT (Table 2) indicated that all groups had elevated RT during HS.

Water intake increased during HS in both CON and BET cows, and a treatment by environment interaction (Table 2) was observed with water intake increasing more in CON cows during HS. However, no linear or quadratic effect was found of dose of BET on water intake (Table 2). In addition, water intake of BET cows was higher during TN compared with CON (Table 2). The cause of the lower water intake of BET-treated cows during HS is unknown; however, it was associated with lower feed intake and RR in BET-treated cows than CON during HS. Feed intake was numerically lower in CON cows during HS, and intake of BET was associated with significantly lower feed intake during HS $(P<0.01 ;$ Table 2). Thus, the increase in water intake in BET-treated cows between environments is not due to higher feed intakes.

Milk yield was numerically higher with MID intake of BET in TN and was significantly higher than CON at the highest intake (Table 2). In addition, a treatment by environment interaction was observed for milk yield $(P=0.05)$ associated with the loss of the milk yield response in cows fed BET during thermal stress. However, no evidence was found of linear or quadratic effects of intake of BET on milk yield. Under HS conditions, milk yield declined in all groups and no differences were found in milk yield between intakes

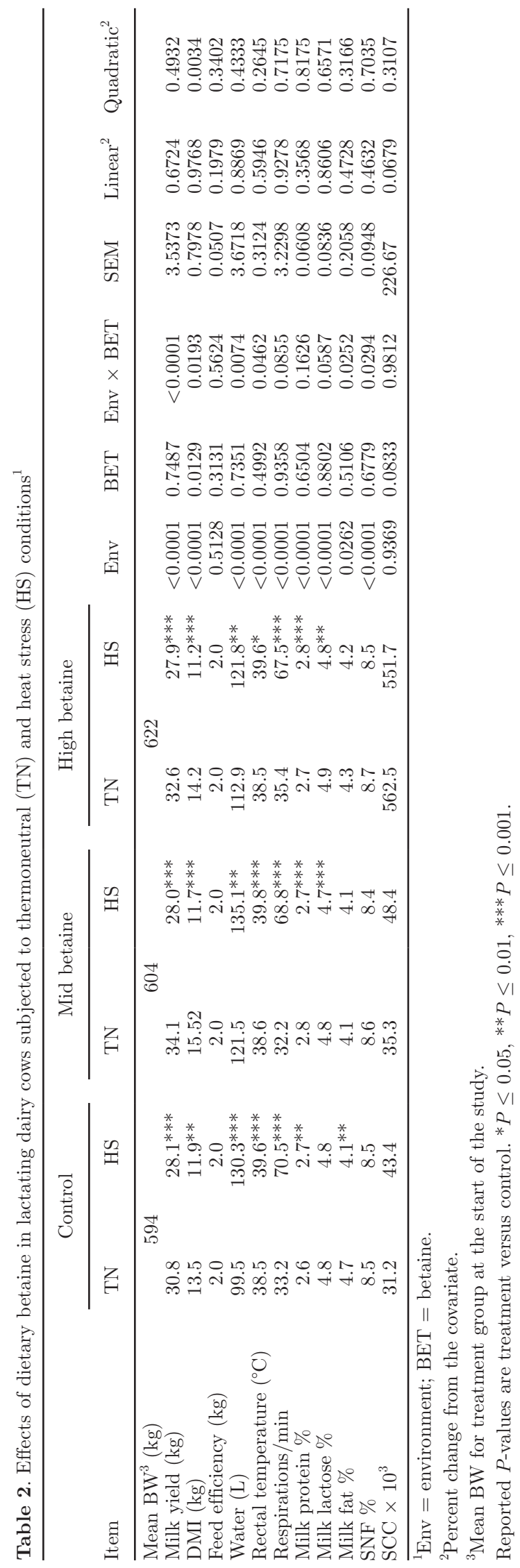


of BET (Table 2). Betaine did not reduce the effect of HS on milk production in lactating dairy cows as expected. The increase in milk production in cows fed BET during TN was lost with HS. We also did not see a difference in feed efficiency between environments or treatments (Table 2).

Betaine had no linear or quadratic effects on milk protein. Lactose and protein \% increased with the MID intake during TN compared with the controls (Table 2 ); however, this effect was not maintained at the HI intake. A quadratic effect was observed of feeding BET on change in milk fat $\%(P<0.04$; Table 2$)$ with milk fat $\%$ declining at the MID intake of BET and rising again at the HI intake (Table 2). However, no overall effect was found of BET intake on fat \% (Table 2). Highly significant effects were found of environment on milk composition (Table 2). Heat stress decreased concentration of lactose, fat, and protein in milk (Table 2), and these effects were not reversed by BET. Somatic cell content of milk was not affected by environment $(P$ $<0.93$ ), but a tendency was found for increased SCC due to intake of BET $(P<0.08)$ as well as a tendency for this effect to be linear with intake of BET $(P<$ 0.07; Table 2). Finally, SNF \% was reduced in milk of CON and BET cows by HS $(P<0.001$; Table 2$)$, and a Trt $\times$ Env interaction was found with SNF \% reduced more in milk from BET cows than CON $(P=0.029$; Table 2). No differences were detected between changes in milk component concentration and milk component yield. Only milk component concentration is given in Table 2.

Serum glucose and insulin levels are shown in Figures 4 and 5. Both increased during HS with BET. No differences were detected in glucose or insulin between intakes of BET during TN. The increase of serum glucose during HS (Figure 4) was greatest in the HI group $(P=$ 0.007) compared with CON. During HS, a treatment effect $(P=0.01)$ was found as insulin (Figure 5) followed glucose and increased with higher intakes of BET.

The expression of HSP27 (Figure 6A) in cells from the plasma sample buffy coat was not different between intakes of BET during $\mathrm{HS}$, but in $\mathrm{TN}$ expression of HSP27 was downregulated (Figure $6 \mathrm{~A} ; P=0.03$ ) in the HI group compared with CON. The expression of HSP70 (Figure 6B) was unaffected by BET in TN and upregulated during HS $(P<0.01$; Figure $6 \mathrm{~B})$.

Betaine did not reduce the effect of $\mathrm{HS}$ in lactating dairy cows as we expected. The advantage in milk production during TN was lost with HS. Dietary BET also improved thermotolerance of lactating dairy cows subjected to HS as measured by reduced RR, reduced water intake, and elevated HSP70 expression in peripheral leukocytes. Cows fed HI BET had significantly

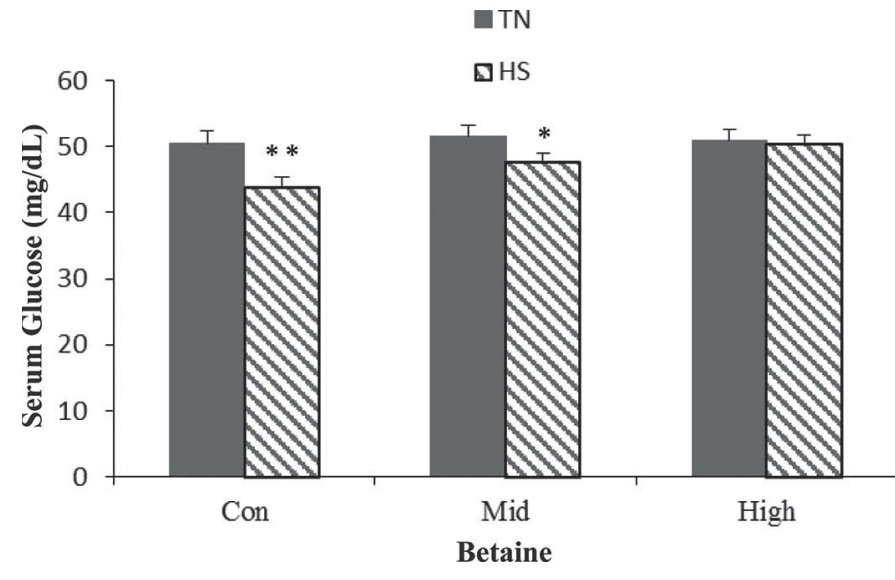

Figure 4. Mean serum glucose with different doses of betaine in thermoneutral (TN) and heat stress (HS). ${ }^{*} P<0.05 ;{ }^{*} P<0.01$ for control $(\mathrm{CON})$ versus high dose of betaine $(\mathrm{HI})$ in $\mathrm{HS}$. Mid $=$ mid intake of betaine. Error bars represent the SE of the LSM.

higher milk production during TN and elevated serum glucose during HS.

Of particular interest is the increase in serum glucose levels of BET-fed cows with the insult of HS. This is even more striking when considering the fact that milk yield declined during $\mathrm{HS}$ as serum glucose levels increased in BET-treated lactating dairy cows during HS. It has been proposed that glucose availability is partially responsible for reduced milk production beyond the decrease in feed intake seen with HS (Baumgard et al., 2011). This study would suggest that the mammary gland is unable to use additional glucose for milk synthesis during HS.

Wang et al. (2010) saw a linear and quadratic increase in ruminal VFA concentration with increasing amounts

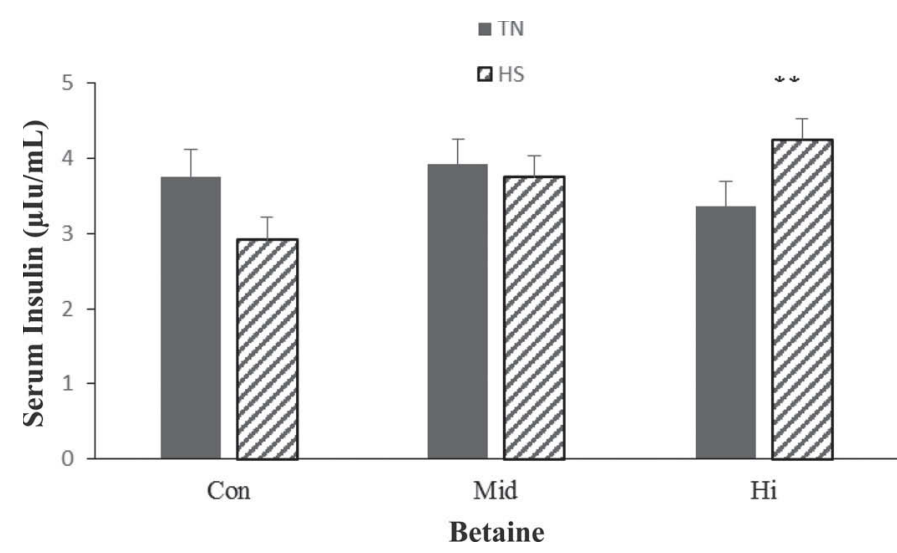

Figure 5. Mean serum insulin with different doses of betaine in thermoneutral (TN) and heat stress (HS). ${ }^{* *} P=0.01$ in high dose of betaine (HI) exposed to HS. Con = control; $\mathrm{Mid}=$ mid intake of betaine. Error bars represent the SE of the LSM. 

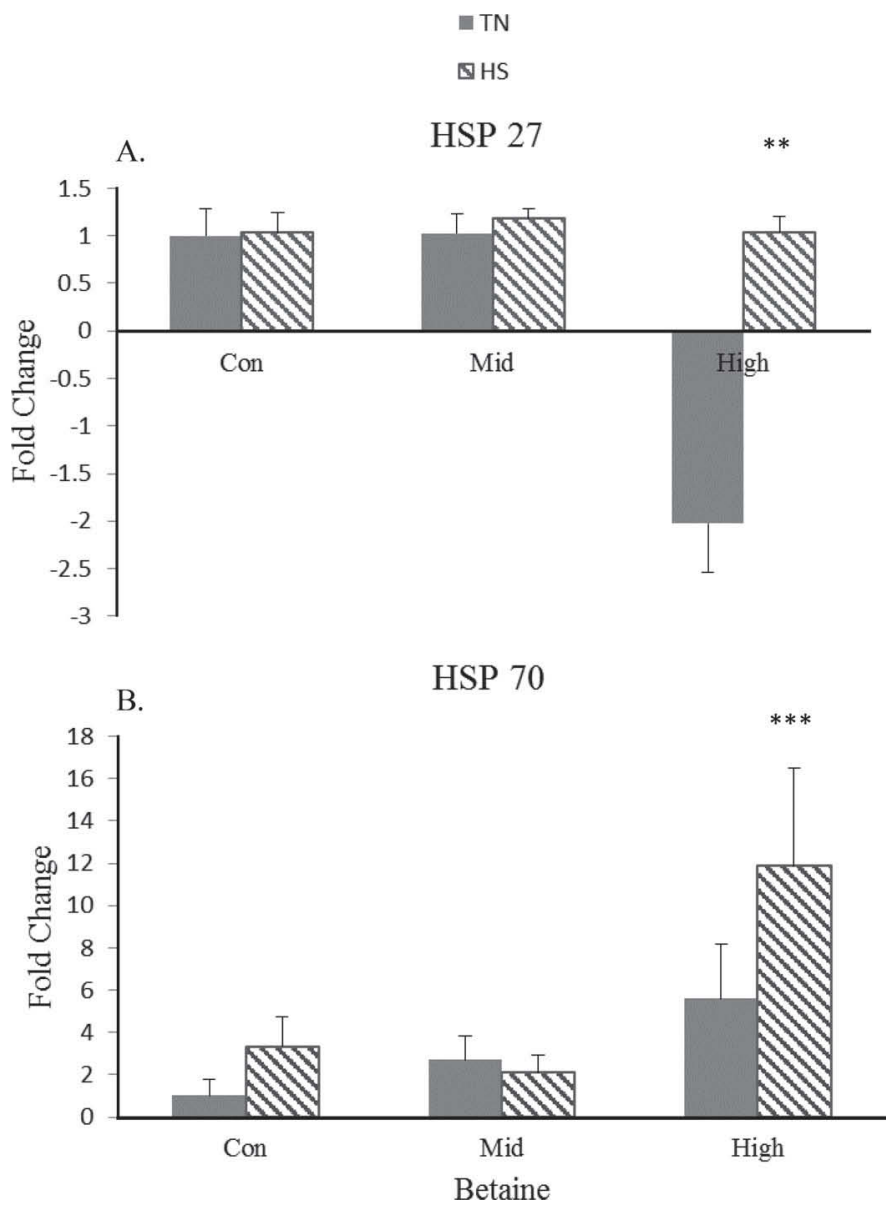

Figure 6. Fold change in heat shock protein (HSP) 27 (A) and HSP70 (B) during thermoneutral (TN) and heat stress (HS) at different levels of betaine. Values are mean gene expression in buffy coat fraction of the blood. ${ }^{* *} P<0.01,{ }^{* * *} P<0.001$. Error bars represent the SE of the LSM.

of dietary BET. The propionate to acetate ratio did not increase, but total VFA concentration was higher. This does not fully explain the higher glucose levels seen in this study, but may reflect the availability of other fuels and precursors. Baumgard et al. (2011) compared the rate of glucose disappearance of lactating dairy cows in both HS and animals kept at TN conditions and pair fed at the levels of the HS cows. The comparison indicated that during HS glucose disappearance was increased and this was associated with higher circulating insulin. These investigators proposed that peripheral glucose utilization was increased during HS during HI BET treatment. Data produced in this study would support that hypothesis because insulin was increased and milk yield was decreased despite increased blood glucose concentrations.

The heat shock gene expression response seen in this study was biphasic. During TN, the expression of HSP27 from the buffy coat fraction in HI cows was downregulated at the HI intake. This may reflect reduced need for chaperone activity and thus a lower expression of HSP27 in BET-treated lactating dairy cows. During HS, HSP70 expression increased at the $\mathrm{HI}$ intake. In the in vitro portion of this work, BMEC also displayed an increased expression of HSP70 when treated with $25 \mathrm{mM}$ BET. The difference in expression of HSP between the MID and HI BET intakes may be indicative of the level of BET that is used, metabolized, or in some way degraded in the rumen. If this is the case, at $57 \mathrm{mg} / \mathrm{kg}$ of BW per day, most of the BET is rumen degraded and at $114 \mathrm{mg} / \mathrm{kg}$ of BW per day, enough BET is making it past the rumen for uptake into host cells. Betaine addition to the diet of lactating dairy cows improved milk and protein yield under TN but not HS conditions. Cows fed BET consumed less water and BET increased serum glucose under HS but not during TN conditions. This suggests that during HS the utilization of glucose by the mammary gland was inhibited.. The inhibition of milk synthesis during stress was proposed by Silanikove et al. (2000) who reported finding a rapid modulation of milk secretion that was stress induced. They reported that this negative feedback system for the mammary gland consisted of a milk enzymatic system (plasminogen activator, plasminogen, and plasmin) that acted on $\beta-\mathrm{CN}$ to form a fragment, $\beta-\mathrm{CN} \mathrm{f}(1-28)$. This fragment bound to the apical plasma membrane of the lactating mammary epithelial cell and closed potassium channels, which subsequently led to inhibition of milk secretion and deterioration of tight junction function (Silanikove et al., 2000). This process would inhibit the utilization of glucose for lactose synthesis, thereby blocking uptake of glucose by the mammary gland.

This proposed system was identified as a potential pathway to rapidly reduce milk secretion in the face of stresses such as HS, dehydration, or severe malnutrition, which present a threat to survival of the animal (Silanikove et al., 2006). The response of the mammary gland to $\beta-\mathrm{CN} \mathrm{f}(1-28)$ was also reported to become more pronounced under stressful conditions, which may be associated with increased receptor localization at the apical surface of the mammary epithelial cell (Silanikove et al., 2006).

\section{ACKNOWLEDGMENTS}

We thank the Department of Agriculture, Australia, for the funding to conduct this study.

\section{REFERENCES}

Baumgard, L. H., J. B. Wheelock, S. R. Sanders, C. E. Moore, H. B. Green, M. R. Waldron, and R. P. Rhoads. 2011. Post absorptive 
carbohydrate adaptations to heat stress and monensin supplementation in lactating Holstein cows. J. Dairy Sci. 94:5620-5633.

Berman, A. 2005. Estimates of heat stress relief needs for Holstein dairy cows. J. Anim. Sci. 83:1377-1384.

Collier, R. J., J. L. Collier, R. P. Rhoads, and L. H. Baumgard. 2008 Genes involved in the bovine heat stress response. J. Dairy Sci. 91:445-454.

Collier, R. J., C. M. Stiening, B. C. Pollard, M. J. VanBaale, L. H. Baumgard, and P. M. Coussens. 2006. Use of gene expression microarrays for evaluating environmental stress tolerance at the cellular level. J. Anim. Sci. 84(E. Suppl.):E1-E13.

Craig, S. A. 2004. Betaine in human nutrition. Am. J. Clin. Nutr. $80: 539-549$.

Diamant, S., N. Eliahu, D. Rosenthal, and P. Goloubinoff. 2001. Chemical chaperones regulate molecular chaperones in vitro and in cells under combined salt and heat stresses. J. Biol. Chem. 276:39586-39591.

Diamant, S., D. Rosenthal, A. Azem, N. Eliahu, A. P. Ben-Zvi, and P. Goloubinoff. 2003. Dicarboxylic amino acids and glycine-betaine regulate chaperone-mediated protein-disaggregation under stress. Mol. Microbiol. 49:401-410.

Hammer, M. A., and J. M. Baltz. 2002. Betaine is highly effective organic osmolyte but does not appear to be transported by established organic osmolyte transporters in mouse embryos. Mol. Reprod. Dev. 62:195-202.

Hernandez, L. L., A. J. Vomachka, R. J. Collier, and N. D. Horseman. 2011. Suppression of lactogenic activity by a selective serotonin reuptake inhibitor (SSRI). J. Endocrinol. 209:45-54.

Lai, S. J., and M. C. Lai. 2011. Characterization and regulation of the osmolyte betaine synthesizing enzymes GSMT and SDMT from halophilic methanogen Methanohalophilus portucalensis. PLoS ONE 6:e25090. http://dx.doi.org/10.1371/journal.pone.0025090.

Laloknam, S., K. Tanaka, T. Buaboocha, R. Waditee, A. Incharoensakdi, T. Hibino, Y. Tanaka, and T. Takabe. 2006. Halotolerant cyanobacterium Aphanothece halophytica contains a betaine transporter active at alkaline $\mathrm{pH}$ and high salinity. Appl. Environ. Microbiol. 72:6018-6026.

Lindstedt, M., S. Allenmark, R. A. Thompson, and L. Edebo. 1990. Antimicrobial activity of betaine esters, quaternary ammonium amphiphiles which spontaneously hydrolyze into nontoxic components. Antimicrob. Agents Chemother. 34:1949-1954.

Livak, K. J., and T. D. Schmittgen. 2001. Analysis of relative gene expression data using real-time quantitative PCR and the $2^{-\Delta \Delta \mathrm{Ct}}$ method. Methods 25:402-408.

Long, N., and D. Schafer. 2013. Sex effects on plasma leptin concentrations in newborn and postnatal beef calves. Prof. Anim. Sci. 29:601-605.

McGrath, M. F. 1987. A novel system for mammary epithelial cell culture. J. Dairy Sci. 70:1967-1981.
Metris, A., S. George, F. Mulholland, A. Carter, and J. Baranyi. 2014. Metabolic shift of Escherichia coli under salt stress in the presence of glycine betaine. Appl. Environ. Microbiol. 80:4745-4756.

Nakai, T., T. Sato, M. Teramura, H. Sadoya, M. Ohtani, T. Takahashi, K. Kida, and S. Hidaka. 2013. The effect of a continuous supply of betaine on the degradation of betaine in the rumen of dairy cows. Biosci. Biotechnol. Biochem. 77:666-669.

Nakanishi, T., R. J. Turner, and M. B. Burg. 1990. Osmoregulation of betaine transport in mammalian renal medullary cells. Am. J. Physiol. 258:F1061-F1067.

Perez, C. C. Koshy, S. Ressl, S. Nicklisch, R. Kramer, and C. Ziegler. 2011. Substrate specificity and ion coupling in the $\mathrm{Na}+$ /betaine symporter BetP. EMBO J. 30:1221-1229.

Peterson, S. E., P. Rezamand, J. E. Williams, W. Price, M. Chahine, and M. A. McGuire. 2012. Effects of dietary betaine on milk yield and milk composition of mid-lactation Holstein dairy cows. J. Dairy Sci. 95:6557-6562.

Petronini, P. G. E. M. De Angelis, A. F. Borghetti, and K. P. Wheeler. 1993. Effect of betaine on HSP70 expression and cell survival during adaptation to osmotic stress. Biochem. J. 293:553-558.

Petronini, P. G., E. M. De Angelis, P. Borghetti, A. F. Borghetti, and K. P. Wheeler. 1992. Modulation by betaine of cellular responses to osmotic stress. Biochem. J. 282:69-73.

Sharma, S. K., P. Christen, and P. Goloubinoff. 2009. Disaggregating chaperones: An unfolding story. Curr. Protein Pept. Sci. 10:432446.

Silanikove, N., U. Merin, and G. Leitner. 2006. Physiological role of indigenous milk enzymes: An overview of an evolving picture. Int. Dairy J. 16:535-545.

Silanikove, N., A. Shamay, D. Shinder, and A. Moran. 2000. Stress down-regulates milk yield in cows by plasmin induced beta-casein product that blocks $\mathrm{K}+$ channels on the apical membranes. Life Sci. 67:2201-2212.

Stiening, C. M., J. B. Hoying, M. B. Abdallah, A. M. Hoying, R. Pandey, K. Greer, and R. J. Collier. 2008. The effects of endocrine and mechanical stimulation on stage I lactogenesis in bovine mammary epithelial cells. J. Dairy Sci. 91:1053-1066.

Wang, C., Q. Liu, W. Yang, J. Wu, W. Zhang, P. Zhang, K. Dong, and Y. Huang. 2010. Effects of betaine supplementation on rumen fermentation, lactation performance, feed digestibilities and plasma characteristics in dairy cows. J. Agric. Sci. 148:487-495.

Wdowiak-Wrobel, S., A. Leszcz, and W. Malek. 2013. Salt tolerance in Astragalus cicer microsymbionts: The role of glycine betaine in osmoprotection. Curr. Microbiol. 66:428-436.

Zimbelman, R. B., R. P. Rhoads, L. H. Baumgard, and R. J. Collier. 2009. Revised temperature humidity index (THI) for high producing dairy cows. J. Dairy Sci. 92(E-Suppl.):347. (Abstr.) 